\title{
ARAŞTIRMA
}

\section{Düşük Risk Myelodisplastik Sendromda Darbepoetin ve Koloni Uyarıcı Faktör Tedavisinin Anemi Üzerine Etkisi}

\author{
The Effect of Darbepoetin and Colony Stimulating \\ Factor Treatment on Anemia in Low Risk \\ Myelodysplastic Syndrome
}

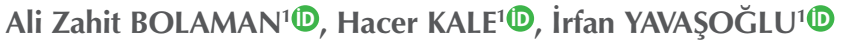 \\ ${ }^{1}$ Adnan Menderes Üniversitesi Tıp Fakültesi, Hematoloji Bilim Dalı, Aydın, Türkiye
}

öz

Amaç: Myelodisplastik sendromlar (MDS) inefektif eritropoez ile karakterize, kendini sitopeni(ler) ile gösteren ve akut lösemiye dönüşebilen bir kök hücre hastalığıdır. Düşük risk MDS hastalarının tedavisinde eritroid uyarııı ilaçların kullanılması hastaları kan transfüzyonu gereksinimini ortadan kaldırabilir. Bu çalışmada refrakter anemi (MDS-RA) ve refrakter anemi ring sideroblast (MDS-RARS) tanılı hastalarımızda darbepoetin tedavisi sonuçlarını rapor ediyoruz.

Hastalar ve Yöntem: WHO 2008-2016 kriterlerine göre MDS-RA ve MDS-RARS tanısı konulan ve darbepoetin 150 mikrogram/hafta ve granülosit koloni uyarıcı faktör (CSF) 30 MÜ/hafta uygulanan hastalar geriye dönük olarak incelendi. Elde edilen sonuçlar 24 hafta süre ile iki haftada bir değerlendirildi.

Bulgular: MDS-RA ve MDS-RARS tanılı 34 MDS hastası değerlendirildi. Hastaların \%76'sında en az bir komorbidite mevcut idi. Darbepoetin ve G-CSF uygulanan hastaların \%64'ünde tedavinin ikinci ayında hemoglobin düzeyinde artma gözlendi.

Sonuç: MDS-RA ve MDS-RARS hastalarında darbopeotin ve G-CSF'nin birlikte kullanılması tolere edilebilen bir tedavidir. Bu ilaçların birlikte kullanılması hemoglobin düzeyinde iyileşme sağlamaktadır.

Anahtar Kelimeler: Darbepoetin; MDS; CSF; Anemi

\section{ABSTRACT}

Objective: Myelodysplastic syndromes (MDS) are a clonal stem cell disaese characterised by ineffective erythropoesis, it appears by cytopenia(s) and can be transforme to acute leukemia. The use of erythroid stimulant agents can elimine the need for blood transfusions in low risk myelodisplastic syndrome. In this sutdy, we report the results of darbepoetin treatment in our patients with MDS-RA and MDS-RARS.

Patients and Methods: The diagnosis of MDS-RA and mDS-RARS was done according to WHO 2008-2016 criterias. Patients who were administered 150 micrograms/week and granulocyte colony stimulating factor $30 \mathrm{MU} /$ week were evaluated retrospectively. The resuls of patients were avaluated at least every two weeks for 24 weeks.

Results: 34 MDS-RA and MDS-RARS patients were evaluated. There was at least one comorbidity in 76 of the patients. Hemoglobin level increased $64 \%$ of patients at second month of darbepoetin and G-CSF treatment.

Conclusion: Darbepoetin and G-CSF treatment is a tolerabl regimen and use of these drugs together improvement on hemoglobin level in patients with MDS-RA and MDS-RARS.

Key Words: Darbepoetin; MDS; CSF; Anemia

Makale atıfı: Bolaman $A Z$, Kale $H$, Yavaşoğlu İ. Düşük risk myelodisplastik sendromda darbepoetin ve koloni uyarıcl faktör tedavisinin anemi üzerine etkisi. LLM Dergi 2020;4(3):39-44.

\section{Yazıșma Adresi}

Prof. Dr. Ali Zahit BOLAMAN

Adnan Menderes Üniversitesi Tıp Fakültesi, Hematoloji Bilim Dalı,

Aydın-Türkiye

Geliş: 01.07.2020 - Kabul: 01.10.2020

E-posta: zahitb@yahoo.com 


\section{GíRiş}

Myelodisplastik sendromlar (MDS) kemik iliği yetersizliği ve akut lösemiye dönüşüm özelliği taşıyan klonal ve heterojen bir hastalık gurubudur. Hastalık inefektif eritropoezin bir sonucu olarak periferik kanda sitopeni kemik iliğinde hipersellülarite ile karakterizedir. Altmış yaş üzeri sık görülür (1). MDS de sitopeni olarak en sık anemi gözlenir. Anemi; izole veya lökopeni ya da trombositopeni ile birlikte olabilir. Hastalarda tanı için en az bir seride azalma olması zorunludur. Semptomlar genellikle halsizlik, yorgunluk, peteşi-purpura ve sitopeni ilişkili enfeksiyon bulgularıdır. MDS'li hastalarda vaskulit, raynaud sendromu, artrit, iritis, serozit gibi otoimmun aracılıklı hastalıklar bulunabilir. Bazen hastalık asemptomatik olup rutin tetkikler esnasında tesadüfen saptanır $(2,3)$.

MDS WHO 2016'da ring sideroblast var ya da yok, tek veya çok seriyi tutan displazi, blast artışı ile beraber olan MDS, izole $5 q$ delesyonu sendromu, çocukluk çağı MDS ve sınıflandırılamayan olmak üzere 8 alt gruptan oluşur. MDS uluslararası prognostik puanlama sistemine risk gurubuna ayrılır. Başlangıçta uluslararası prognostik skorlama sistemi (IPSS) kullanılır iken 2008 yılından itibaren lösemi tanısı için periferik kan veya kemik iliğinde blast oranının eşik değer olarak \%20 alınması nedeni ile IPSS revize (IPSS-R) edilmiştir. IPSS-R'e göre hastalık çok düşük, düşük, orta, yüksek, çok yüksek risk gruplarına ayrılır. Bu risk gruplarına göre çok düşük ve düşük risk gruplarında yaşam süresi 5-8 yıl; buna karşın yüksek ve çok yüksek risk gruplarında 0.8-1.6 yıldır $(4,5)$.

Refrakter anemilerin olduğu düşük risk hasta gruplarındaki halsizlik anemi ile ilişkilidir. Bu hasta gruplarında anemiye yaklaşım NCCN; ESMO, ELN kılavuzlarında özetlenmiştir. Birbirine benzeyen bu üç kılavuzda da yalnız başına veya G-CSF ile birlikte eritropoetin düzeyi < $500 \mathrm{IU} / \mathrm{L}$ olan hastalarda Eritropetin alfa veya Darbepoetin kullanılması önerilmektedir (6-8). Biz bu yazımızda Darbepoetin alan hasta sonuçlarını rapor ediyoruz.

\section{HASTALAR ve YÖNTEM}

Ocak 2014 ve 2017 yılları arasında Aydın Adnan Menderes Üniversitesi Erişkin Hematoloji Bilim Dalı'nda WHO 2008-2016'ya göre refrakter anemi (MDS-RA) ile refrakter anemi-ring sideroblast (MDS-RARS) tanısı konulan hastalar çalışmaya alındı. Tanı Maygrunwald-Giemza ile boyanan periferik yayma, kemik iliği aspirasyonu ve kemik iliği demir boyamasının tecrübeli en az iki hematolog ve kemik iliği aspirasyon-biyopsisi hematoksilen eozin ve demir boyası ile boyanarak hematopatolog tarafından değerlendirilmesi; kemik iliği aspirasyonu örneğinde demir boyama da sideroblast $>\% 15$ görülmesi ile de sideroblastik anemi tanısı konuldu (9). Hastaların kemik ilik örnekleri kromozom analizi için genetik bölümüne gönderildi. Hastaların tümünde eritropoetin düzeyi < $500 \mathrm{mU} / \mathrm{L}$ idi. Tedaviye başlamak için Darbepoetin'in endikasyon zorunluluğu şartlarına uyuldu. Hastalarda hemoglobin $(\mathrm{hb})>10 \mathrm{gr} / \mathrm{dL}$ olanlarda dört hafta içinde $\mathrm{hb}$ artışı $>2 \mathrm{gr} / \mathrm{dl}$ 'den fazla ise doz \%25 oranında azaltıldı. Darbepoetin tedavisinde hb 11-12 gr/dL arasında tutulmaya çalışıldı. G-CSF 30 MÜ haftada 1 kez deri altına uygulama şeklindeydi. Periferik kanda lökosit > 15.000/ mikrolitre olan hastalarda doz azaltıldı. Hastalarda Hb 12 $\mathrm{gr} / \mathrm{dl}$ üzerinde olan hastalarda da Darbepoetine ara verildi. $\mathrm{Hb}<9 \mathrm{gr} / \mathrm{dl}$ altında olan ve anemiyi tolere edemeyen hastalarda eritrosit süspansiyonu verildi. Cevap elde edilen hastalarda tedaviye yanıtsızlık oluşana kadar devam edildi. Major yanit olarak Eritropoetin tedavisi seyrinde 4 hafta öncesi var olan transfüzyon gereksiniminin ortadan kalkması ve $\mathrm{hb} \geq 2 \mathrm{gr} / \mathrm{dL}$ artması (transfüzyonsuz) kabul edildi. En az 8 hafta süre ile haftada 1 kez deri altına darbepoetin $150 \mu \mathrm{gr}$ uygulandı. Elde edilen yanıtlar iki haftalık aralıklar ile takip edildi. Hastalar eritropoetin aldığı sürece demir eksikliği anemisi yönünden takip edildi. Nutrisyonel anemisi (B12 vitamini, folik asit ve demir eksikliği), kronik hastalık anemili (örneğin böbrek yetmezliği, romatoid artrit), kontrolsüz hipertansiyonlu ve tromboembolik atak geçiren, konjestif kalp yetmezliği ve disritmisi olan, tedavi için azasitidin, desitabin, lenalidomide kullanan hastalar çalışmaya dahil edilmedi. Çalışma Adnan Menderes Etik Kurulu tarafından Protokol No: 2020/115, 13 nolu karar ile onaylandı. Tüm veriler Windows 19.0 PASW kullanılarak analiz edildiO (SPSS Inc., Chicago, IL, USA). Gruplar arası kıyaslamada Mann-Whitney U testi kullanıldı. Sonuçlar 595 güven aralığında değerlendirildi ve 0.05 'ten küçük değerler anlamlı olarak kabul edildi.

\section{BULGULAR}

Toplam 34 hasta geriye doğru değerlendirildi (Tablo 1). Kadın erkek oranları birbirine yakındı. Hastalara MDS tanısından sonra geçen darbepoetin başlama zamanı ortanca 2 hafta idi. Hastaların 19'una 2. haftada, 9'una 3. haftada, 4 hastaya 4. haftada ve 2 hastaya 5 . haftada tedavi başlandı. Başvuru anında ortanca hb düzeyi $9 \mathrm{gr} / \mathrm{dL}$ idi. Tedavinin 4. haftasında hb düzeyinde $1.2 \mathrm{gr} / \mathrm{dl}$ artma gözlendi (Tablo 2). Hemoglobin düzeyinde artış 8 . haftada 1.9 gram/dL'e ulaştı. Hastalarda 8. haftadan itibaren hb düzeyindeki artış

Tablo 1. Hastaların cins ve yaş'a göre hb düzeyleri

\begin{tabular}{lccccc} 
Sayı & Cinsiyet K/E & Yaş & RA & RARS & Hb \\
\hline 34 & $18 / 16$ & $71(44-85)$ & 26 & 8 & $9(6.7-10.9)$ \\
\hline K: Kadın, E: Erkek, RA: Dirençli anemi, RARS: Dirençli anemi ring sideroblast. & & &
\end{tabular}


Tablo 2. Darbepoetin tedavisinde haftalar içinde hemoglobin düzeyinde artış

\begin{tabular}{lcc} 
Süre & $\begin{array}{c}\text { Tüm Hastalar Hb düzeyi gr/dl } \\
\mathbf{n}: \mathbf{3 4}\end{array}$ & $\begin{array}{c}\text { Cevap veren hastalar Hb düzeyi gr/dl } \\
\mathbf{n : 2 2}(\mathbf{\%} 64)\end{array}$ \\
\hline Tedavi öncesi & $9(6.7-10.9)$ & $9.3(7.4-10.4)$ \\
4. hafta & $10.2(6.9-14.3)$ & $11.6(8.6-14.3)$ \\
8. hafta & $10.9(8-15)$ & $11.6(9-14)$ \\
16. hafta & $10.5(7-13)$ & $11.3(8.6-13)$ \\
24. hafta & $10.3(7.1-13)$ & $11.3(9.1-13)$
\end{tabular}

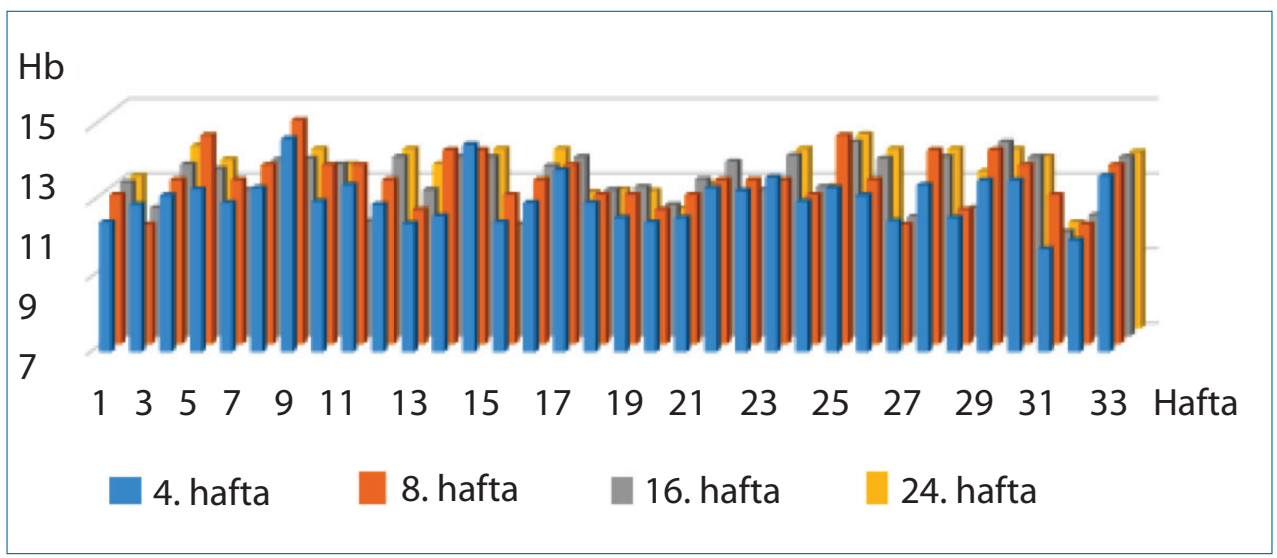

Şekil 1. Hastaların eritropoetin tedavisine verdiği yanıtlar.

nispeten daha az idi. 16. haftada hb $10.5 \mathrm{gr} / \mathrm{L}$ iken 24. haftada hb $10.3 \mathrm{gr} / \mathrm{dL}$ olmuştu (Tablo 3). 34 hastanın 22'sinde (\%64) yanıt elde edildi. Tedaviye yanıt elde edilen grupta tedavinin 4. haftasında hemoglobin artışı $2.3 \mathrm{gr} / \mathrm{dL}$ idi. Hastalar 8. haftaya ulaştığında hb düzeyindeki $2.3 \mathrm{gr} / \mathrm{dL}$ düzeyi korunuyordu. Ancak 16. haftada hb düzeyindeki artış 2 gr ile sınırlı idi. Cevap elde edilen hastaların tümünde 4 hafta içinde anemiye ait semptomlar kayboldu ve eritrosit transfüzyonuna bağımlılıkları ortadan kalktı. Hastalarda elde edilen ortanca yanıt süresi 22.5 (17-25) ay idi. Mevcut komorbiditeler sırası ile hipertansiyon 12 (\%35), diabet 7 (\%20.5), KOAH 3 hastada (\%8.8) idi. Tedavi sırasında 4 hastada yan etki gözlendi. Sırası ile deride eritem, 1 hastada hipertansiyon gelişimi, 1 hastada hipertansiyonu kontrolü için ilave ilaç kullanma ihtiyacı ve 1 hastada da bel ağrısı ortaya çıktı. Eritropoetin aldığı süre içinde hiçbir hastada demir eksikliği anemisi gelişmedi. Hastaların konvansiyonel kromozom analizlerinde 27 hastada sonuç elde edilemedi; 7 hastada ise sonuçlar normal olarak rapor edildi.

\section{TARTIŞMA ve SONUÇ}

MDS hastalarında yaşam kalitesini bozan en önemli faktör hastaların \%90'unda bulunan anemidir. Hastaların ileri yaşta olmaları ve ilave komorbiditeleri nedeni ile daha fazla klinik şikayete neden olmaktadır. Anemi; düşük risk MDS hastalarında transfüzyon ve eritropoezi uyarıcı ajanlar (EUA) ile tedavi edilmektedir. Bazı hastalarda lenalidomid ve hipometilize edici ajanlar anemi için yararlı olabilmektedir (10).
MDS'li hastalarda eritrosit transfüzyonu için iki yaklaşım mevcuttur. Liberal yaklaşımda $\mathrm{hb}<9 \mathrm{gr} / \mathrm{dL}$; katı yaklaşım gösteren grupta ise $\mathrm{hb}>7 \mathrm{gr} / \mathrm{dL}$ altında olduğunda transfüzyon yapılması önerilir. Amerikan kan bankası transfüzyon için hb eşiğini $<7$ gr/dL (kanıt düzeyi IA), kardiyovasküler hastalık var ise $<8 \mathrm{gr} / \mathrm{dL}$ (kanıt düzeyi $2 \mathrm{~B}$ ) ve semptomlara bakarak karar vermeyi (kanıt düzeyi 2C) kriter olarak kabul etmektedir (11).

MDS hastalarında kan transfüzyonu bazı sorunları da beraberinde getirir. Bunlar; demir yüklenmesi, viral enfeksiyonlar, tranfüzyon ilişkili akut akciğer hasarı (TIAAH), transfüzyona bağlı dolaşım yüklenmesi (TBDY) ve ateştir. Transfüzyona bağlı viral enfeksiyon tarama yöntemlerinde iyileşme nedeni ile son yıllarda az görülmektedir. Ancak TIAAH ve TBDY hala önemli bir sorundur. Transfüzyonun önemi bir diğer komplikasyonu vücutta demir birikimidir. Verilen her 1 Ü eritrosit süspansiyonu vücutta 200 mg demir birikimine neden olmaktadır. Demir toksik bir maddedir, vücutta birikimi lizozomal ruptür, hücre ve doku hasarına neden olur. Demir birikimi bilhassa karaciğer ve kalpte gerçekleşir. Kalpte demir birikimi hastalarda disritmiye ve kalp fonksiyonlarında bozukluğa neden olabilmektedir. Hastalarda hastane bağımlılığı oluşabilir. Tüm bu nedenler ile düşük risk MDS hastalarındaki anemi tedavisinde ilk seçenek olarak transfüzyon tercih edilmemelidir $(12,13)$. 
Myelodisplastik sendromlu hastalarda endojen eritropoetin yanıtı bozuktur. MDS hastalarında kemik iliğindeki eritropoetin reseptörlerinde yapısal defekt nedeni ile eritropoetine bağı sinyal sistemi bozulmuştur. Bazı araştırmacılar hematopoetik öncü hücrelerde prematür apopitoz oluştuğunu rapor etmişlerdir. EUA'lar epoetin alfa, epoetin beta, epoetin zeta, epoetin teta ve uzun etkili olan darbepoetin alfadır. Ülkemizde sadece epoetin alfa, epoetin beta ve darbepoetin mevcuttur. Eritropoetin'in MDS de kullanılan hasta sayısı başlangıçta azdır. Bu nedenle 1990-1994 yılları arasında eritropoetin verilen hastalara ait metanaliz ilk kez 1994'de yapılmıştır. Bu çalışma 205 hastayı içeren 17 araştırmanın sonucunu vermektedir. Buna göre hastaların \%16'sında eritropoetin kullanılması ile anemide düzelme olmaktadır. Bu çalışmanın en önemli özelliği Eritropoetin düzeyinin $200 \mathrm{mIU} / \mathrm{L}$ olan hastalarda başarı oranının yüksekliğidir (14). Bu metanalizden sonra yapılan 3 çalışmada MDS'de anemili hastalarda \%28-\%45 yanıt elde edilebileceğini rapor etmiştir (15-17).

1997-2008 yılları arasında eritropoetin ile ilişkili 5 araştırma yayınlanmıştır. Bu çalışmaların en önemli özelliği hastalarda eritropoein ile birlikte CSF kullanılmasıdır. Tedavide kullanılan eritropoetin dozu 60-300 U/kg/gün, CSF dozu ise 30-150 ug/gün idi. Hastalarda elde edilen yanıt oranları \%38-70 arasında bulunmuştur. Bu çalışmalarda bir tanesi hariç tümünde CSF'nin yanıt oranını artırdığı gözlendi ve lösemik dönüşüme katkısının olmadığı rapor edildi (1822). Eritoproetin alfa ile iki faz 3 çalışma yapılmıştır $(22,23)$. Greenberg ve arkadaşları (23) MDS'li hastalarda CSF veya CSF olmaksızın eritropoetin alfa $300 \mathrm{lU} / \mathrm{kg} / \mathrm{gün}$ dozunda kullanmış ve CSF kullanılan hastalarda \%36 kullanmayanlarda ise \%9.6 yanıt elde etmiştir.

EPOANE çalışması 180 hasta üzerinde plasebo'ya karşılık eritropoetin alfa'nın 2:1 şeklinde randomizasyonu şeklinde yapılan faz 3 çalışmadır. Bu çalışmada eritropoetin alfa ile elde edilen yanıt oranı \%31.8'e karşılık pleasebo da \%4.4'tür (24). Ancak bu iki çalışmanın eleştirilebilecek yanı eritropoetin tedavisinin tüm risk gruplarına verilmesidir. Hastalarda bilhassa hematolojik yan etki oranları beklenenden yüksektir (23).

Darbepoetin ile yapılan çalışmalar 2005 yılından itibaren başlamıştır. Stasi ve arkadaşları (25) MDS'i hastalarda darbopoetin'in 150 mikrogram/hafta uygulanması ile $\% 45$ oranında yanıt elde etmiştir. Daha sonra yapılan 5 adet faz 2 çalışmada $\% 49$ ve $\% 72$ arasında cevap elde edilmiştir. Darbepoetin kullanan hastaların tedavisine CSF ilave edildiğinde yanıt oranı \%22 oranında artmaktadır (26-30). Darbepoetin bu çalışmalarda haftada 1 kez 150 mikrogram dozunda kullanılmıştır. Darbepoetin ile ilişkili bir faz 3 çalışma bulunmaktadır. Bu çalışmada darbepoetin'in 3 haftada
1 kez 500 mikrogram kullanılmasının etkinliği araştırılmış; darbepoetin alan hastalarda transfüzyon intiyacı azalmış eritropoetine yanıt \%37 olarak rapor edilmiştir. Elde edilen yanıt özellikle eritropoetin düzeyi $<100 \mathrm{IU} / \mathrm{L}$ olan hastalarda belirgindir. Çalışma tasarımın da hastalık gurubunun homojen olmaması çalışmanın eleştirilmesi gereken bir özelliğidir (31). Yapılan bir meta analizde; eritropoetin düzeyi < $100 \mathrm{IU} / \mathrm{L}$, transfüzyon yapılmayan veya çok az yapılan ve kemik iliği \%5 altında olan MDS hastalarında istatistiksel olarak Darbepoetin'in etkili olduğu gösterilmiştir (31).

Bizim çalışmamızda karyotip analizi olmaması nedeni ile sadece WHO 2008'e göre MDS-RA ve MDS-RARS tanılı hastaları içermesi ve blast artışı > \%5 olan orta-yüksek risk gurubu hastalarının çalışmaya dahil edilmemesi ve hiçbir tedavi almamış olması yanında başlangıçtan itibaren CSF'in birlikte kullanılması nedeni ile literatürdeki vakalara göre daha üniform bir hasta grubunu içermekteydi. Darbepoetin ve CSF kullanılan hastalarda elde edilen majör yanıt oranı \%64 idi. Şimdiye kadar yapılan çalışmalarda hastalar majör yanıt değil majör ve minör yanıt oranlarının toplam (total yanıt) oranları değerlendirilmiştir. Biz çalışmamızda sadece majör yanıt veren hasta oranlarını inceledik, minör yanıt elde edilen hastaları değerlendirmedik. Elde ettiğimiz yanıt oranın majör yanıt sonucu olması nedeni ile önemli olduğu kanaatindeyiz. Çalışmamızda CSF ile birlikte kullanılan Darbepoetin'in hastalarda ilk 4 haftada yanıt elde edilmesi literatür bilgilerinden farklı olarak hızlı bir yanıtı göstermektedir. Bunun nedeninin hasta grubunun iyi seçilmesi ve başlangıçtan itibaren CSF ve Darbepoetin'in birlikte kullanılmasıdır. Hastalarda bu tedavi sırasında çok ciddi yan etki olmaması, hastaların transfüzyon olmaksızın yaşamını sürdürmesi tedavinin değerini artıran özelliklerdir. Ancak sitogenetik değerlendirmenin olmaması çalışmamızın en önemli kısıtlayıcı yönü idi.

Sonuç olarak bu çalışma tedavi almamış MDS-RA ve MDS-RARS hastalarında G-CSF ve darbepoetin tedavisi etkin, kısa sürede yanıt oluşumu sağlayan ve yan etkileri kabul edilebilir olduğunu göstermektedir. Bu konuda prospektif randomize çalışmaların yapılması yararlı olacaktır.

\section{ETIK KURUL ONAYI}

Çalışma Adnan Menderes Etik Kurulu tarafından onaylandı. (Karar no: 2020/115-13 Tarih: 22.06.2020).

\section{ÇIKAR ÇATIŞMASI}

Yazarların çıkar çatışması bulunmamaktadır.

\section{MALI AÇIKLAMA}

Çalışma için doğrudan veya dolaylı mali destek alınmadı. Çalışma ile ilgili herhangi bir firma veya kişi ile ilgili ticari bağlantı yoktur. 


\section{YAZAR KATKISI}

Literatür taranması: AZB; Verilerin Toplanması: AZB, IY, HK; Makalenin Yazımı: AZB; Onaylama: AZB, IYY.

\section{KAYNAKLAR}

1. Zini G. Diagnostics and prognostication of myelodysplastic syndromes, Ann Lab Med. 2017;37:465-74.

2. Bolaman Z, Bilgir O, Ayyıldız O. Myelodisplastik sendromlar. T Klinik Tıp Bilimleri Dergisi. 1994;21:21-32.

3. Ades L, Itzykson R, Fenaux P. Myelodysplastic syndromes. Lancet. 2014;383:2239-52.

4. Montalban-Bravo G, Garcia-Manero G. Myelodysplastic syndromes: 2018 update on diagnosis, risk-stratification and management. Am J Hematol. 2018;93:129-47.

5. Steensm DP. Does early diagnosis and treatment of myelodysplastic syndromes make a difference? Best Pract Res Clin Haematol. 2019;32:101099.

6. Greenberg PL, Stone RM, Al-Kali A, Barta SK, Bejar R, Bennett JM, et al. Myelodysplastic syndromes, version 2.2017, NCCN clinical practice guidelines in oncology. J Natl Compr Cancer Netw. 2017;15:60-87.

7. Fenaux P, Haase D, Sanz GF, Santini V, Buske C, ESMO Guidelines Working Group. Myelodysplastic syndromes: ESMO Clinical Practice Guidelines for diagnosis, treatment and follow-up. Ann Oncol. 2014;25(Suppl 3):iii57-69.

8. Malcovati L, Hellström-Lindberg E, Bowen D, Adès L, Cermak J, Del Cañizo C, et al. European Leukemia N (2013) Diagnosis and treatment of primary myelodysplastic syndromes in adults: recommendations from the European Leukemia Net. Blood. 2013;122:2943-64.

9. Swerdlow $\mathrm{SH}, \mathrm{Campo}$, Harris NL, Jaffe ES, Pileri SA, Stein $\mathrm{H}$, et al. WHO Classification of Tumors of Haematopoietic and Lymphoid Tissues. Lyon, France: International Agency for Research on Cancer; 2008.

10. Bewersdorf JP, Zeidan AM. Evolving therapies for lower-risk myelodysplastic syndromes. Ann Hematol. 2020;99:677-92.

11. Carson JL, Terrin ML, Noveck H, Sanders DW, Chaitman BR, Rhoads GG, et al. Liberal or restrictive transfusion in high-risk patients after hip surgery. N Engl J Med. 2011;365:2453-62.

12. Buelvas AC. Anemia and transfusion of red blood cells. Colombia Médica. 2013;44:236-42.

13. Carson JL, Grossman BJ, Kleinman S, Tinmouth AT, Marques MB, Fung $M K$, et al. Red blood cell transfusion: a clinical practice guideline from the AABB. Ann Intern Med. 2012;157:49-58.

14. Hellstrom-Lindberg E. Efficacy of erythropoietin in the myelodysplastic syndromes: a meta-analysis of 205 patients from 17 studies. Br J Haematol. 1995;89:67-71.

15. Rose EH, Abel RI, Nelson RA, McCullough DM, Johnson RW. The use of $\mathrm{r}$-HuEpo in the treatment of anaemia related to myelodysplasia (MDS). Br J Haematol. 1995;89:831-7.

16. Terpos E, Mougiou A, Kouraklis A, Chatzivassili A, Michalis E, Giannakoulas $\mathrm{N}$, et al. Prolonged administration of erythropoietin increases erythroid response rate in myelodysplastic syndromes: a phase II trial in 281 patients. Br J Haematol. 2002;118:174-80.
17. Italian cooperative study group for rhuepo in myelodysplastic syndromes. A randomized double-blind placebo-controlled study with subcutaneous recombinant human erythropoietin in patients with low-risk myelodysplastic syndromes. $\mathrm{Br} J$ Haematol. 1998:103;1070-4

18. Hellström-Lindberg $E$, Negrin R, Stein R, Krantz $S$, Lindberg G, Vardiman J, et al. Erythroid response to treatment with G-CSF plus erythropoietin for the anaemia of patients with myelodysplastic syndromes: proposal for a predictive model. $\mathrm{Br} J$ Haematol. 1997;99:344-51.

19. Hellström-Lindberg E, Ahlgren T, Beguin Y, Carlsson M, Carneskog J, Dahl IM, et al. Treatment of anemia in myelodysplastic syndromes with granulocyte colony-stimulating factor plus erythropoietin: results from a randomized phase II study and long-term follow-up of 71 patients. Blood. 1998; 92:68-75.

20. Remacha AF, Arrizabalaga B, Villegas A, Manteiga R, Calvo T, Julià $A$, et al. Erythropoietin plus granulocyte colony-stimulating factor in the treatment of myelodysplastic syndromes. Identification of a subgroup of responders. The Spanish Erythropathology Group. Haematologica. 1999;84:1058-64.

21. Balleari E, Rossi E, Clavio M, Congiu A, Gobbi M, Grosso M, et al. Erythropoietin plus granulocyte colony-stimulating factor is better than erythropoietin alone to treat anemia in low-risk myelodysplastic syndromes: results from a randomized single-centre study. Haematologica. 2006;85:174-80.

22. Jädersten M, Malcovati L, Dybedal I, Della Porta MG, Invernizzin $\mathrm{R}$, Mongomery SM, et al. Erythropoietin and granulocyte-colony stimulating factor treatment associated with Improved survival in myelodysplastic syndrome. J Clin Oncol. 2008;26:3607-13.

23. Greenberg PL, Sun Z, Miller KB, Bennett JM, Tallman MS, Dewald $G$, et al. Treatment of myelodysplastic syndrome patients with erythropoietin with or without granulocyte colony-stimulating factor: results of a prospective randomized phase 3 trial by the Eastern Cooperative Oncology Group (E1996). Blood. 2009;114:2393-400

24. Fenaux P, Santini V, Aloe Spiriti MA, Giagounidis R, Schlag A, Radinoff $A$, et al. Randomised, double-blind, placebo-controlled, multicenter study evaluating epoetin alfa versus placebo in anemic patients with IPSS Low-Int1 risk MDS. Leukemia. 2018;32:2648-58.

25. Stasi R, Abruzzese E, Lanzetta G, Terzoli E, Amadori S. Darbepoetin alfa for the treatment of anemic patients with low- and intermediate-1-risk myelodysplastic syndromes. Ann Oncol. 2005;16:1921-7.

26. Gabrilove J, Paquette R, Lyons RM, Mushtaq C, Sekeres MA, Tomita $D$, et al. Phase 2 , single-arm trial to evaluate the effectiveness of darbepoetin alfa for correcting anaemia in patients with myelodysplastic syndromes. Br J Haematol. 2008;142:379-93.

27. Villegas A, Arrizabalaga B, Fernández-Lago C, Castro M, Mayans $J R$, González-Porras JR, et al. Darbepoetin alfa for anemia in patients with low or intermediate-1 risk myelodysplastic syndromes and positive predictive factors of response. Curr Med Res Opin. 2011;27:951-60.

28. Gotlib J, Lavori P, Quesada S, Stein RS, Shahnia S, Greenberg PL. A Phase II intra-patient dose-escalation trial of weight-based darbepoetin alfa with or without granulocyte-colony stimulating factor in myelodysplastic syndromes. Am J Hematol. 2009;84:15-20. 
29. Nilsson-Ehle $H$, Birgegård $G$, Samuelsson J, Antunovic P, Astermark J, Garelius H. Quality of life, physical function and MRIT2* in elderly low-risk MDS patients treated to a haemoglobin level of $\geq 120 \mathrm{~g} / \mathrm{l}$ with darbepoetin alfa \pm filgrastim or erythrocyte transfusions. Eur J Haematol. 2011;87:244-52.

30. Kelaidi C, Beyne-Rauzy O, Braun T, Sapena R, Cougou P, Adès L. High response rate and improved exercise capacity and quality of life with a new regimen of darbepoetin alfa with or without filgrastim in lower-risk myelodysplastic syndromes: a phase II study by the GFM. Ann Hematol. 2013;92:621-31.
31. Platzbecker U, Symeonidis S, Oliva EN, Goede JS, Delforges $M$ Mayera J, et al. A phase 3 randomized placebo-controlled trial of darbepoetin alfa in patients with anemia and lower-risk myelodysplastic syndromes. Leukemia. 2017;31:1944-50.

32. Park S, Fenaux P, Greenber P, Mehta B, Callaghan F, Kim C, et al. A phase 3 randomized placebo-controlled trial of darbepoetin alfa in patients with anemia and lower-risk myelodysplastic syndromes. Leukemia. 2017;31:1944-50. 